\title{
Bevacizumab in pleural mesothelioma: too few, too late?
}

\author{
Jan P. van Meerbeeck, Birgitta I. Hiddinga \\ Thoracic Oncology, Antwerp University Hospital, Belgium \\ Correspondence to: Jan P. van Meerbeeck. Thoracic Oncology, Antwerp University Hospital, Belgium. Email: jan.van.meerbeeck@uza.be.
}

Submitted Mar 26, 2016. Accepted for publication Apr 06, 2016.

doi: $10.21037 /$ tcr.2016.04.02

View this article at: http://dx.doi.org/10.21037/tcr.2016.04.02

The French Cooperative Thoracic Intergroup recently reported the mature results of its Mesothelioma Avastin Cisplatin Pemetrexed Study (MAPS) (1). The investigators are to be commended for the outstanding design, conduct and analysis of this investigator initiated trial, which they claim will lead to a much needed improvement in the treatment paradigm for this dreadful disease. Let's review the reported evidence and address its internal and external validity.

A total of 448 eligible patients were randomly allocated to a standard backbone of cisplatin-pemetrexed with (PCB) or without (PC) the addition of the monoclonal antibody bevacizumab, targeting the circulating vascular endothelial growth factor (VEGF), which is the ligand for its homonymous receptor (VEGF-R) in the hallmark angiogenic pathway. In the intention-to-treat analysis, $26 \%$ of the patients allocated to PCB were still alive after a median of 18.8 months, compared to $21 \%$ of those in the PC arm (Table 1). This difference in outcome is statistically significant and results in a reduction in absolute and relative risk of $6 \%$ and $27 \%$, respectively, in favour of the combination treatment. After an initial crossing, both survival curves clearly separate with a persisting benefit for PCB. The effect is also present in progression-free survival and in the preplanned subgroup analyses according to various prognostic patient and tumor variables. Patientreported outcomes as measured with the LCSS-MESO and symptom scores at baseline and at different time points thereafter, do not show any significant change but for fatigue, which was borderline significantly more improved with PCB, nine weeks after the initial assessment. Although the treatment was overall well tolerated, the expected class specific side-effects of bevacizumab resulted in more grade 3 and 4 toxicities in the combination arm. No data on quality adjusted life years (QALY) or health costs are yet available.
Although the unblinded nature of the study and the lack of the use of a placebo cast a shadow on the validity of some weaker secondary endpoints, the use of overall survival as primary endpoint corrects this.

The magnitude of the observed benefit in overall survival is the largest ever reported in randomized intervention trials in mesothelioma, and would have qualified this treatment for immediate registration in the past. In the mean time, we have met far better improvements with other hallmarktargeted agents in the $1^{\text {st }}$ line treatment of patients with lung cancer, e.g. erlotinib and crizotinib $(2,3)$. The number of mesothelioma patients needed to treat with bevacizumab in order to have 1 more alive at 18 months is 18 and compares unfavourably with those other targeted agents. When applying ESMO's recently published guidelines for prioritizing the registration of novel anti-cancer medication, bevacizumab in mesothelioma would obtain a score 3 , for a hazard ratio of 0.77 in a palliative setting with an overall survival of less than year in the control arm, but without improvement in quality of life or decrease in grade 3-4 toxicity (4). With this score, bevacizumab would not qualify for priority registration by health authorities, for which the threshold is now 4 out of a maximum of 5 , regardless of the actual cost.

Strikingly, the patients in the control arm of MAPS perform better than their counterparts in other randomized trials with a cisplatin-based doublet, suggestive of a selection bias (5-7). The rechallenge with pemetrexed or a platinum-containing doublet might be responsible for this observed paradoxical improvement in overall survival. With all caveats surrounding inter-trial comparisons, an imbalance in known prognostic factors as histological subtype, performance status and thrombocytosis is the more likely reason (Table 2). The available data do not allow to compare the stage at diagnosis, so we might assume that 
Table 1 Endpoints of MAPS (1)

\begin{tabular}{|c|c|c|c|}
\hline Endpoint/treatment arm & $\begin{array}{l}\text { Cisplatin-pemetrexed } \\
\qquad(\mathrm{n}=225)\end{array}$ & $\begin{array}{l}\text { Cisplatin-pemetrexed- } \\
\text { bevacizumab }(n=223)\end{array}$ & Statistical significance \\
\hline Overall survival, median (m) $(95 \% \mathrm{Cl})$ & $16.1(14-17.9)$ & $18.8(15.9-22.6)$ & HR 0.77 (0.62-0.95) \\
\hline Grade 3-4 adverse events (\%) & 62 & 71 & NR \\
\hline $\begin{array}{l}\text { Improvement of global health status at } 9 \text { weeks } \\
\text { (\% of patients) }\end{array}$ & 23 & 23 & $P=0.95$ \\
\hline Improvement of fatigue at 9 weeks (\% of patients) & 18 & 28 & $P=0.046$ \\
\hline
\end{tabular}

MAPS, Mesothelioma Avastin Cisplatin Pemetrexed Study; HR, hazard ratio; NR, not reported; Cl, confidence intervals.

Table 2 Randomized trials with a cisplatin doublet in MPM: characteristics and outcome

\begin{tabular}{|c|c|c|c|c|}
\hline \multirow{2}{*}{ Characteristics } & \multicolumn{4}{|c|}{ Trial (reference) } \\
\hline & JMIG (8) & CALGB (9) & CBP501 (10) & MAPS (1) \\
\hline $\mathrm{N}$ of patients & 226 & 58 & 23 & 225 \\
\hline Treatment intensity & $\begin{array}{c}\text { Median number of } \\
\text { cycles } 6[1-12]\end{array}$ & $\begin{array}{l}\text { Median number of } \\
\text { cycles } 6[2-39]\end{array}$ & $44 \%$ received 6 cycles & $76 \%$ received 6 cycles \\
\hline Median age (y) (range) & 61 [29-85] & 65 (NR) & 66 [35-84] & $65.7(60.8-70.3)$ \\
\hline Caucasian race (\%) & 90.3 & 90 & 87 & NR \\
\hline Epithelioid histotype (\%) & 68 & 67 & 70 & 81 \\
\hline TNM stage 1-2 (\%) & 22.7 & NR & NR & NR \\
\hline Smokers (\%) & NR & NR & NR & 57 \\
\hline Anemia (\%) & NR & NR & NR & 71 \\
\hline Thrombocytosis (\%) & NR & 40 & NR & 27 \\
\hline Overall survival, median (m) $(95 \% \mathrm{Cl})$ & $12.1(10-14.4)$ & $14.7(10.3-20)$ & $12.8(6.5-16.1)$ & $16.1(14-17.9)$ \\
\hline
\end{tabular}

MPM, malignant pleural mesothelioma; Cl, confidence intervals; NR, not reported.

the French participants had a substantially overall lower tumor burden and a better performance, as reflected by the fact that a vast majority underwent a thoracoscopy and 3 out of 4 received six cycles of chemotherapy. Whether the routine talc pleurodesis associated with the thoracoscopy might have impacted on survival, is unproven and unlikely. The authors claim that this selection is further due to a lesser practice of radical surgery in French compared to US mesothelioma patients, shifting fit operable patients towards palliative chemotherapy. Patients with low burden of disease and good performance status are indeed candidate for radical surgery either by extrapleural pneumonectomy or, increasingly, pleurectomy/decortication (9). Randomized trials addressing the effectiveness of radical surgery in mesothelioma should hence from now on preferably include a control arm with cisplatin/pemetrexed and bevacizumab. Whether the same should apply to trials with palliative intent remains controversial, as this would restrict the inclusion to a sample of patients, which is not representative of the disease in the population as a whole.

So, the MAPS-evidence is applicable to fit young mesothelioma patients, with low comorbidity, able to 
withstand a thoracoscopy and six cycles of a cisplatinbased chemotherapy. Unfortunately, the average patient in most thoracic oncology practices is $70+$ and has a smoking related cardiovascular comorbidity precluding him/her from the abovementioned interventions. But even in this patient, a benefit of adding bevacizumab to a carboplatinbased doublet is likely, although to a lesser degree. There is consensus that both regimens, cis- and carboplatin with pemetrexed have equivalent effectiveness but a different toxicity spectrum (8). This assumption would imply a broad registration of bevacizumab with carboplatin, whereas the present evidence was obtained with cisplatin.

Implicit to the concept of targeted therapy, one might expect that the expression of a biological target-either circulating VEGF or another downstream intracellular pathway biomarker-would be mandatory in selecting patients for this treatment (10). Low VEGF level was however, found to be prognostic but not predictive of the effect of bevacizumab. This unfortunate finding follows similar observations with bevacizumab in lung cancer and other solid tumours, making it a targeted treatment without measurable target (11). The role of bevacizumab in lung cancer is indeed controversial: whilst in combination with carboplatin and paclitaxel, a significant benefit in outcome was reported, this could not be confirmed in combination with cisplatin and gemcitabine $(12,13)$. This finding, together with a negative outcome of the same combination in mesothelioma, suggests a possible negative pharmacologic interaction between gemcitabine and bevacizumab.

Nintedanib is an oral pan-kinase inhibitor, which among others, inhibits the VEGFR-2 receptor on the endothelial cells, and has hence anti-angiogenic properties. The drug has been registered for the second line treatment of non-squamous NSCLC in combination with docetaxel and is currently being added to a cisplatin/pemetrexed $1^{\text {st }}$ line backbone in a randomized trial in mesothelioma (NCT01907100). Although here too, an upfront target biomarker for patient selection is lacking, the results of this trial could bring the necessary confirmation of the role of anti-angiogenic agents in mesothelioma.

In conclusion, the IFCT has added a significant contribution to the treatment of mesothelioma. Although the internal validity of MAPS is good, this improvement might however, be considered 'too few, too late' in an increasingly budget-sensitive environment (14). For the time being and pending further confirmatory evidence, bevacizumab's indication in mesothelioma should best be restricted to patients closely resembling those included in MAPS.

\section{Acknowledgements}

None.

\section{Footnote}

Provenance: This is a Guest Editorial commissioned by Section Editor Yue-Can Zeng, MD, PhD (Associate professor, Department of Medical Oncology, Cancer Center, Shengjing Hospital of China Medical University, Shenyang, China).

Conflicts of Interest: The authors have no conflicts of interest to declare.

\section{References}

1. Zalcman G, Mazieres J, Margery J, et al. Bevacizumab for newly diagnosed pleural mesothelioma in the Mesothelioma Avastin Cisplatin Pemetrexed Study (MAPS): a randomised, controlled, open-label, phase 3 trial. Lancet 2015. [Epub ahead of print].

2. Rosell R, Carcereny E, Gervais R, et al. Erlotinib versus standard chemotherapy as first-line treatment for European patients with advanced EGFR mutation-positive non-small-cell lung cancer (EURTAC): a multicentre, open-label, randomised phase 3 trial. Lancet Oncol 2012;13:239-46.

3. Solomon BJ, Mok T, Kim DW, et al. First-line crizotinib versus chemotherapy in ALK-positive lung cancer. N Engl J Med 2014;371:2167-77.

4. Cherny NI, Sullivan R, Dafni U, et al. A standardised, generic, validated approach to stratify the magnitude of clinical benefit that can be anticipated from anti-cancer therapies: the European Society for Medical Oncology Magnitude of Clinical Benefit Scale (ESMO-MCBS). Ann Oncol 2015;26:1547-73.

5. Kindler HL, Karrison TG, Gandara DR, et al. Multicenter, double-blind, placebo-controlled, randomized phase II trial of gemcitabine/cisplatin plus bevacizumab or placebo in patients with malignant mesothelioma. J Clin Oncol 2012;30:2509-15.

6. Vogelzang NJ, Rusthoven JJ, Symanowski J, et al. Phase III study of pemetrexed in combination with cisplatin versus cisplatin alone in patients with malignant pleural mesothelioma. J Clin Oncol 2003;21:2636-44. 
7. Krug LM, Wozniak AJ, Kindler HL, et al. Randomized phase II trial of pemetrexed/cisplatin with or without CBP501 in patients with advanced malignant pleural mesothelioma. Lung Cancer 2014;85:429-34.

8. Ceresoli GL, Zucali PA, Mencoboni M, et al. Phase II study of pemetrexed and carboplatin plus bevacizumab as first-line therapy in malignant pleural mesothelioma. Br J Cancer 2013;109:552-8.

9. Hiddinga BI, van Meerbeeck JP. Surgery in mesothelioma--where do we go after MARS? J Thorac Oncol 2013;8:525-9.

10. Sledge GW Jr. What is targeted therapy? J Clin Oncol 2005;23:1614-5.

Cite this article as: van Meerbeeck JP, Hiddinga BI. Bevacizumab in pleural mesothelioma: too few, too late? Transl Cancer Res 2016;5(2):120-123. doi: 10.21037/tcr.2016.04.02
11. Daenen LG, Voest EE. Finding Predictive Biomarkers for Anti-Vascular Endothelial Growth Factor Treatment: A Mission Impossible? ASCO Educational book 2011:429-33.

12. Sandler A, Gray R, Perry MC, et al. Paclitaxel-carboplatin alone or with bevacizumab for non-small-cell lung cancer. N Engl J Med 2006;355:2542-50.

13. Reck M, von Pawel J, Zatloukal P, et al. Phase III trial of cisplatin plus gemcitabine with either placebo or bevacizumab as first-line therapy for nonsquamous non-small-cell lung cancer: AVAil. J Clin Oncol 2009;27:1227-34.

14. Baas P, van Meerbeeck J. Money rules the world. Lung Cancer 2016;91:77-8. 